
\title{
3 Research Square \\ Percutaneous Osteoplasty under Fluoroscopy and Cone-Beam CT guidance for Painful Sternal Metastases
}

\author{
Xun-wei Liu \\ 960th Hospital of PLA \\ Zhi-guo Wang \\ 960th Hospital of PLA \\ Jin Peng \\ 960th Hospital of PLA \\ Gang Sun ( $\square$ cjr.sungang@vip.163.com ) \\ 960th Hospital of PLA
}

\section{Research Article}

Keywords: Osteoplasty. Bone metastasis, Pain, Palliative Care, Sternum.

Posted Date: June 11th, 2021

DOI: https://doi.org/10.21203/rs.3.rs-576606/v1

License: (a) (i) This work is licensed under a Creative Commons Attribution 4.0 International License. Read Full License 


\section{Abstract}

Background: Although percutaneous osteoplasty (POP) has been widely accepted and is now being performed for the treatment of painful bone metastases outside the spine, there are only scarced reports regarding osteoplasty in painful sternal metastases.

Case presentation: The paper reported four patients with painful sternal metastasis who underwent POP under fluoroscopic and cone-beam CT guidance. The patients were three men and one woman (mean age, 66.25 years). Primary tumor location in lung is 3 cases, in thyroid is 1 case. In these cases, Pain was measured using a numerical rating scale (NRS), with scores ranging from 0 (no pain) to 10 (worst pain imaginable). The scores on the NRS in the four patients before POP were 9, 8, 8, and 9. After POP, the NRS scores decreased to 2, 3, 2, and 2, respectively, in follow-up at 6 months.

Conclusions: POP is a safe and effective treatment for pain caused by metastatic bone tumors in the sternum. However, care and at tention should be paid to the insertion of a needle and cement distribution for better treatment effect

\section{Introduction}

Percutaneous osteoplasty (POP) has been widely accepted and is now being performed for the treatment of painful bone metastases outside the spine. (1-3). The technique consists of inserting a percutaneous needle into the affected bones and the injection of polymethylmethacrylate (PMMA). However, there are only scarced reports regarding osteoplasty in painful sternal metastases (4-8). We present here four patients with painful sternal metastases who were successfully treated by POP under fluoroscopic and cone-beam CT guidance.

\section{Material And Methods}

This retrospective study was approved by our institutional review board. The clinical and imaging data of the four cases underwent POP were reviewed. Informed consent for the procedure was obtained from all four patients.

The indication for POP was severe bone pain caused by sternal metastatic disease. The pain was refractory to pain medication including parenteral narcotic treatment. POP was offered as a treatment to the patients with a muti-interdisciplinary consensus among a team of surgeons, oncologists and radiotherapists. POP procedures were performed by interventional radiologists with more than 5 years of experience in bone procedures in a digital subtraction angiography system with cone-beam CT (CBCT). Conscious sedation was achieved just before the procedure and patients were placed in a supine position with neck in slight extension. After chest wall sterile preparation and draping, cone-beam CBCT was performed to identify the margins of the metastases and delineate the most appropriate needle trajectory and needle inclination by a superior to inferior approach. With local anesthesia, a 13-gauge bone-beveled needle was punctured into the sternum, and gently advanced into the lesion under direct real-time 
fluoroscopic guidance and cardiovascular monitoring. Depending on the sizes and shapes of lesions, 24 needles per lesion were placed percutaneously to get better distribution of the bone cement. Polymethyl methacrylate (PMMA) was mixed to a semiliquid consistency. PMMA injection was performed by means of 1-mL syringes with a maximal possible amount via the needle and the cement contained in the lumen of the needle was delivered into the lesion by introducing a stylet into the needle under real-time fluoroscopic guidance. If cement achieved satisfactory filling in the metastatic area, or reached the anterior and posterior cortical margin, or started to leak, the injection would be stopped. The volume of injected cement was determined and recorded. Additional CBCT or computed tomography (CT) scan was performed to evaluate the distribution of PMMA in the lesions.

A series of clinical assessment for the treatment effect was recoded at pretherapy baseline, and at 1 week, 1 month, 3 months and 6 months after procedure. Pain was measured using a numerical rating scale (NRS) with scores ranging from 0 (no pain) to 10 (worst pain imaginable).

Table 1 shows the clinical characteristics of four patients that included: gender, age, histology of the lesion, number of needles inserted, amount of injected PMMA, changes in pain intensity and pain medication (oral narcotic or transdermal narcotic). Table 2 shows the NRS scores at baseline, and at 1 week, 1 month, 3 months and 6 months after procedure.

Table 1

Patient data are detailed.

\begin{tabular}{|c|c|c|c|c|c|c|c|}
\hline Case & $\begin{array}{l}\text { VAS } \\
\text { before }\end{array}$ & primary tumour & $\begin{array}{l}\text { VAS } \\
\text { before }\end{array}$ & $\begin{array}{l}\text { Previous } \\
\text { analgesic } \\
\text { therapy }\end{array}$ & $\begin{array}{l}\text { needle } \\
\text { number }\end{array}$ & $\begin{array}{l}\text { Amount of } \\
\text { injected } \\
\text { PMMA } \\
(\mathrm{ml})\end{array}$ & $\begin{array}{l}\text { Analgesic } \\
\text { therapy } \\
\text { after } \\
\text { procedure }\end{array}$ \\
\hline 1 & $\mathrm{M} / 71$ & $\begin{array}{l}\text { Squamous cell } \\
\text { carcinoma of the } \\
\text { lung }\end{array}$ & 9 & $\begin{array}{l}\text { Oral } \\
\text { narcotic }\end{array}$ & 2 & 2.5 & none \\
\hline 2 & $\mathrm{~F} / 57$ & $\begin{array}{l}\text { Adenocarcinoma } \\
\text { of the lung }\end{array}$ & 8 & $\begin{array}{l}\text { Oral } \\
\text { narcotic }\end{array}$ & 3 & 4.5 & none \\
\hline 3 & $\mathrm{M} / 72$ & $\begin{array}{l}\text { Squamous cell } \\
\text { carcinoma of the } \\
\text { lung }\end{array}$ & 8 & $\begin{array}{l}\text { Transdermal } \\
\text { narcotic }\end{array}$ & 2 & 1.5 & none \\
\hline 4 & $M / 65$ & $\begin{array}{l}\text { Papillary } \\
\text { carcinoma of the } \\
\text { thyroid }\end{array}$ & 9 & $\begin{array}{l}\text { Transdermal } \\
\text { narcotic }\end{array}$ & 2 & 2 & none \\
\hline
\end{tabular}


Table 2

Numerical rating scale (NRS) scores of patients at preoperative and each postoperative follow-up point

\begin{tabular}{|llllll|}
\hline Case & Pre-procedure & \multicolumn{3}{l}{ Poste-procedure } \\
\cline { 3 - 6 } & & 1 week & 1month & 3months & 6months \\
\hline 1 & 9 & 4 & 3 & 3 & 3 \\
\hline 2 & 8 & 3 & 2 & 2 & 2 \\
\hline 3 & 8 & 4 & 3 & 3 & 3 \\
\hline 4 & 9 & 3 & 2 & 2 & 2 \\
\hline
\end{tabular}

\section{Case Presentation}

\section{Case 1}

A 71-year-old man complainted of persistent pain and braced himself, when coughing. Upon examination, there was pinpoint tenderness over the sternum. On CT scan, there was a lesion measured $5.4 \otimes 4.7 \nabla 3.9$ $\mathrm{cm}$ in left lung hilum with an osteolytic destruction of the sternal manubrium. The biopsy of lung lesion confirmed squamous cell carcinoma. The patient had a NRS score of 9, and no symptom improvement was obtained with oral narcotic. POP was performed with three needles inserted, and $2.5 \mathrm{ml}$ of PMMA was injected into the sternal lesion (Fig. 1). After the procedure, he gained a significant pain relief, and the NRS scores decreased to $4,3,3$, and 3, respectively, in follow-up at 1 week, 1 month, 3month, and 6 month.

\section{Case 2}

A 57-year-old woman had a five-year history of right pulmonary adenocarcinoma and treated with neoadjuvant chemotherapy followed by radiotherapy. One month ago, she had severe pain in the anterior chest wall that often affected her sleep. The patient had a NRS score of 8 , and the pain was refractory to oral narcotics. CT scan showed multifocal destructive osteolytic lesions of the sternal body and manubrium. POP was performed with three needles inserted and $4.5 \mathrm{ml}$ of PMMA was injected (Fig. 2). After the procedure, she gained pain relief and was able to sleep well, and the NRS scores decreased to 3 , 2,2 , and 2, respectively, in follow-up at 1 week, 1 month, 3 month, and 6 month.

\section{Case 3}

A 72-year-old man had persistent pain of the anterior chest wall that worsened with body position change. The patient had a NRS score of 8 , and the pain was refractory to transdermal narcotic treatment. On CT scan, there was a lesion measured $3.7 \otimes 5.5 \otimes 4.3 \mathrm{~cm}$ in left lower lung with an osteolytic destruction of the sternal body. The biopsy of lung lesion confirmed adenocarcinoma. POP was performed with two needles inserted and $1.5 \mathrm{ml}$ of PMMA was injected (Fig. 3). After the procedure, he 
obtained pain relief, and changing body position didn't cause pain. His NRS scores decreased to $4,3,3$, and 3 , respectively, in follow-up at 1 week, 1 month, 3month, and 6 month.

\section{Case 4}

A 65-year-old man underwent a thyroidectomy 19 years ago for an undifferentiated carcinoma. He was hospitalized for his anterior chest wall severe pain with NRS score of 9 , and no pain relief was gained with transdermal narcotic. His focal anterior chest wall pain corresponded to an osteolytic sternal body metastasis on CT scan. POP was performed through two needles insertion and $2 \mathrm{ml}$ of PMMA injection. The patient achieved pain relief after the procedure (Fig. 4), and the NRS scores decreased to 3, 2, 2, and 2 , respectively, in follow-up at 1 week, 1 month, 3 month, and 6 month.

\section{Discussion}

Osseous metastase are usually seen in cancer patients at advanced stage. It usually causes intractable pain, functional impairment, and worsening quality of life. Because most of the patients with intractable painful metastases are usually at the end stage of disease at the time of presentation, the goals of treating these patients should be the alleviation of pain, and improvement of life quality. The patients are usually not surgical candidates, and have complications for routine analgesic medications. Currently, radiation is recognized as the most effective treatment, however, $20-30 \%$ of patients with painful bone metastases are nonresponders (9). Furthermore, sternal radiation may result in devastating cardiac complications due to its proximity to the heart and large vasculatures. Patients can also develop acute pneumonitis and esophageal complications during and after radiation therapy $(10,11)$.

The sternum is a long flat bone, only $2-3 \mathrm{~cm}$ in depth. Percutaneous insertion of a needle into the sternal lesion can be a challenge because of the contour deformity and the bony landmarks sabotage by lytic tumor. To meet this challenge, some imaging guidance technology has been applied to accurately and precisely perform insertion of a needle through minimally invasive means with use of both $\mathrm{CT}$ and fluoroscopic guidance with sonography or CBCT $(7,12-15)$. We perfer to use the fluoroscopy and CBCT guidance to improve preprocedural trajectory planning, needle advancement tracking of and cement distribution through the sternum, to reduce the complexity of multiple device applications.

Physical and chemical properties of cement injected alone into osteolytic lesions can provide mechanical resistance to axial compressive forces, but less so to tension and torques stresses (16-18). Hence, several techniques for bone metastases were reported that included the use of cemented screws, nails, catheters and metallic mesh (19-23). Additionally, some studies showed feasibility and effectiveness for the treatment of painful bone metastases with kyphoplasty, radiofrequency thermal ablationor microwave ablation and cementoplasty (4-6). Because of the non-weight-bearing sternum and the advanced disease at the time of presentation, we think POP can be used instead of above more expensive and complicated techniques, achieving the pain palliation and life quality improvement with less complication. 
To perform POP for sternal metastatic lesion, multiple puncture may be necessary to get a more adequate coverage of the bone lesion. In this study, all patients had great pain caused by osteolytic lesion in the sternum and the invasion of the cortex, and often exaggerated by respirational motion of the rib cage. Our use of POP on sternal metastases resulted in satisfying clinical outcome regarding analgesic therapy management, pain control and mobility improvement. The analgesic efficacy was maintained at 6-month follow-up in all four cases. The POP was technically successful in all cases, and without severe complications.

At present, POP technique with the advantage of rapid relieve pain has been used to treat osteolytic lesions in clinical practice. The analgesic effect may be attributed to the stabalization of microfractures of the bone, the destruction of nerve endings through the exothermic reaction and cytotoxicity $(24,25)$. However, these are still unclear that the detail analgesic effect and the optimal volume of injected PMMA. The patient 3 obtained good pain relief in the present series, POP only injected $1.5 \mathrm{ml}$ PMMA into the larger lesion area.The result may verify Yamada' study that a small amount PMMA can still achieved pain relief (26).

In conclusion, we described good pain-relieving effects following POP in four patients with metastatic tumors in sternum. POP to sternal matastases may be an effective and safe palliative therapy for reducing pain and improving patients' quality of life and mobility.

\section{Declarations}

\section{Ethics Approval And Consent}

This retrospective study was approved by the review board of the 960th Hospital of Joint Logistics Support Force of PLA (No: ChiCTR2000032667). Informed consent for the procedure was obtained from all the four patients.

\section{Consent for publication}

Written informed consent for publication (including images, case history and data) was obtained from all the four patients.

\section{Availability of Data and materials}

The manuscript data can be copyed and redistributed.

\section{Competing interests}

The authors declare that they have no competing interests.

\section{Funding}




\section{Authors' contributions}

GS designed the research project. XL and ZW prepared the manuscript. PJ and LY collected the data and analyze the data. All authors read and approved the final manuscript.

\section{Acknowledgements}

Not applicable

\section{References}

1. Kelekis A, Lovblad KO, Mehdizade A, Somon T, Yilmaz H, Wetzel SG, et al. Pelvic osteoplasty in osteolytic metastases: technical approach under fluoroscopic guidance and early clinical results. J Vasc Interv Radiol. 2005;16:81-8. doi:10.1097/01.RVI.0000141717.84515.92.

2. Hierholzer J, Anselmetti G, Fuchs H, Depriester C, Koch K, Pappert D. Percutaneous osteoplasty as a treatment for painful malignant bone lesions of the pelvis and femur. J Vasc Interv Radiol. 2003;14:773-7. doi:10.1097/01.rvi.0000079987.80153.85.

3. Sun G, Jin P, Liu XW, Li M, Li L. Cementoplasty for managing painful bone metastases outside the spine. Eur Radiol. 2014;24:731-7. doi:10.1007/s00330-013-3071-z.

4. Masala S, Manenti G, Roselli M, Mammucari M, Bartolucci DA, Formica V, et al. Percutaneous combined therapy for painful sternal metastases: a radiofrequency thermal ablation (RFTA) and cementoplasty protocol. Anticancer Res. 2007;27:4259-62. PMID: 18214029.

5. Deib G, Deldar B, Hui F, Barr JS, Khan MA. Percutaneous microwave ablation and cementoplasty: clinical utility in the treatment of painful extraspinal osseous metastatic disease and myeloma. AJR Am J Roentgenol. 2019;27:1-8. doi:10.2214/AJR.18.20386.

6. Shah RV. Sternal kyphoplasty for metastatic lung cancer: image-guided palliative care, utilizing fluoroscopy and sonography. Pain Med. 2012;13:198-203. doi:10.1111/j.1526-4637.2011.01299.x.

7. Zhou B, Wu CG, Li MH, Gu YF, Cheng YD. Percutaneous osteoplasty for painful sternal lesion from multiple myeloma. Skeletal Radiol. 2009;38:281-25. doi:10.1007/s00256-008-0620-7.

8. Poussot B, Deschamps F, Varin F, Abed A, Moulin B, Prud'homme C, et al. Percutaneous Fixation by Internal Cemented Screws of the Sternum. Cardiovasc Intervent Radiol. 2020;43:103-9. doi:10.1007/s00270-019-02334-2.

9. Gianfelice D, Gupta C, Kucharczyk W, Bret P, Havill D, Clemons M, et al. Palliative treatment of painful bone metastases with MR imaging-Guided focused ultrasound. Radiology. 2008;249:355-63. doi:10.1148/radiol.2491071523. 
10. Tang D, Peng EW, Giri D, Chowdhary M, Sarkar P. Mediastinal irradiation and its effect on the cardiovascular system. Br J Hosp Med (Lond). 2009;70:222-4. doi:10.12968/hmed.2009.70.4.41626.

11. Adams MJ, Hardenbergh PH, Constine LS, Lipshultz SE. Radiation-associated cardiovascular disease. Crit Rev Oncol Hematol. 2003;45:55-5. doi:10.1016/s1040-8428(01)00227-x.

12. Pusceddu C, Fancellu A, Ballicu N, Fele RM, Sotgia B, Melis L. CT-guided percutaneous screw fixation plus cementoplasty in the treatment of painful bone metastases with fractures or a high risk of pathological fracture. Skeletal Radiol. 2017;46:539-45. doi:10.1007/s00256-017-2584-y.

13. Strobl FF, Haeussler SM, Paprottka PM, Hoffmann RT, Pieske O, Reiser MF, et al. Technical and clinical outcome of percutaneous CT fluoroscopy-guided screw placement in unstable injuries of the posterior pelvic ring. Skeletal Radiol 2014;::1093 - 100. doi: 10.1007/s00256-014-1890-x.

14. Anselmetti GC, Manca A, Ortega C, Grignani G, Debernardi F, Regge D. Treatment of extraspinal painful bone metastases with percutaneous cementoplasty: a prospective study of 50 patients. Cardiovasc Intervent Radiol. 2008;31:1165-73. doi:10.1007/s00270-008-9396-3.

15. Roux C, Tselikas L, Yevich S, Sandes Solha R, Hakime A, Teriitehau C, et al. Fluoroscopy and conebeam CT-guided fixation by internal cemented screw for pathologic pelvic fractures. Radiology. 2019;290:418-25. doi:10.1148/radiol.2018181105.

16. Gangi A, Buy X. Percutaneous bone tumor management. Semin Intervent Radiol. 2010;27:124-36. doi:10.1055/s-0030-1253511.

17. Heini PF, Franz T, Fankhauser C, Gasser B, Ganz R. Femoroplasty- augmentation of mechanical properties in the osteoporotic proximal femur: a biomechanical investigation of PMMA reinforcement in cadaver bones. Clin Biomech. 2004;19:506-12. doi:10.1016/j.clinbiomech.2004.01.014.

18. Sutter EG, Mears SC, Belkoff SM. A biomechanical evaluation of femoroplasty under simulated fall conditions. J Orthop Trauma. 2010;24:95-9. doi:10.1097/BOT.0b013e3181b5c0c6.

19. Kelekis A, Filippiadis D, Anselmetti G, Brountzos E, Mavrogenis A, Papagelopoulos P, et al. Percutaneous augmented peripheral osteoplasty in long bones of oncologic patients for pain reduction and prevention of impeding pathologic fracture: the rebar concept. Cardiovasc Intervent Radiol. 2016;39:90-6. doi:10.1007/s00270-015-1138-8.

20. Kim JH, Kang HG, Kim JR, Lin PP, Kim HS. Minimal invasive surgery of humeral metastasis using flexible nails and cement in high-risk patients with advanced cancer. Surg Oncol. 2011;20:e32-7. doi:10.1016/j.suronc.2010.09.001.

21. Anselmetti GC, Manca A, Chiara G, Tutton S, lussich G, Gino G, et al. Painful pathologic fracture of the humerus: percutaneous osteoplasty with bone marrow nails under hybridcomputed tomography and fluoroscopic guidance. J Vasc Interv Radiol. 2011;22:1031-4. doi:10.1016/j.jvir.2011.02.021.

22. Liu XW, Jin P, Liu K, Chen H, Li L, Li M, et al. Comparison of percutaneous long bone cementoplasty with or without embedding a cement-filled catheter for painful long bone metastases with impending fracture. Eur Radiol. 2017;27:120-7. doi:10.1007/s00330-016-4347-x. 
23. Deschamps F, Farouil G, Hakime A, Teriitehau C, Barah A, de Baere T. Percutaneous stabilization of impending pathological fracture of the proximal femur. Cardiovasc Intervent Radiol. 2012;35:142832. doi:10.1007/s00270-011-0330-8.

24. Baroud G, Samara M, Steffen T. Influence of mixing method on the cement temperature-mixing time history and doughing time of three acrylic cements for vertebroplasty. J BiomedMater Res B Appl Biomater. 2004;68:112-6. doi:10.1002/jbm.b.20009.

25. Belkoff SM, Molloy S. Temperature measurement during polymerization of polymethylmethacrylate cement used for vertebroplasty. Spine (Phila Pa 1976). 2003; 28:1555-9. PMID: 12865844.

26. Yamada K, Matsumoto Y, Kita M, Yamamoto K, Kobayashi T, Takanaka T. Long-term pain relief effects of four patients undergoing percutaneous vertebroplasty for metastatic vertebral tumor. $J$ Anesth. 2004;18:292-5. doi:10.1007/s00540-004-0252-6.

\section{Figures}

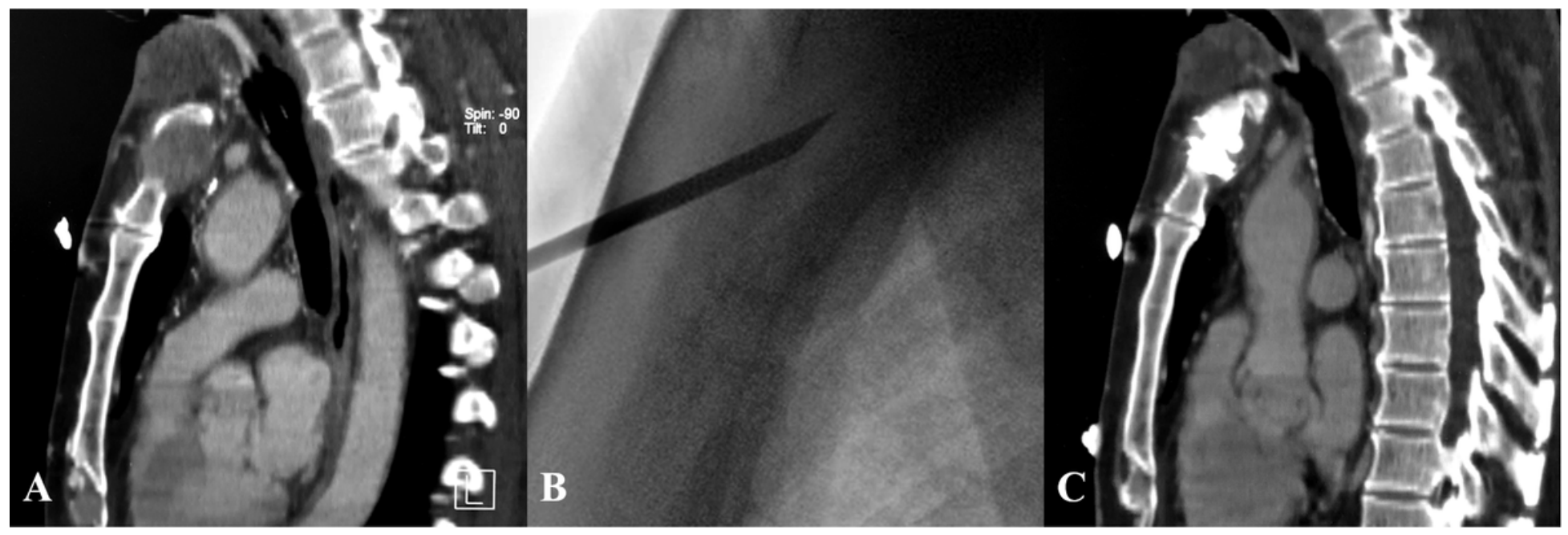

\section{Figure 1}

(A) CT sagital image demonstrated an osteolytic metastatic lesionin the sternal manubrium. (B) Radiograph showed the first needle inserted into the center of the lesion. (C) CT sagital image, PMMA distribution. 


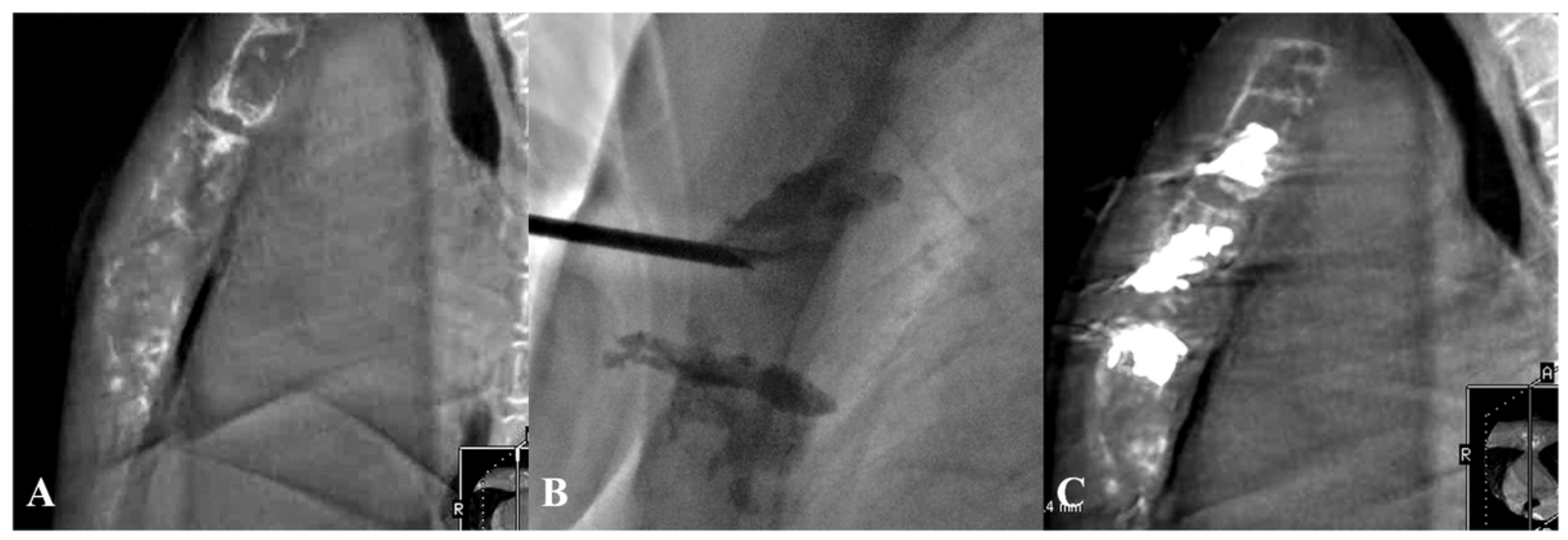

Figure 2

(A) CBCT sagital image showed a diffuse osteolytic lesion of the sternal body and manubrium. (B) Radiograph showed the third needle inserted into the center of the lesion. (C) CBCT sagital image showed PMMA distribution.

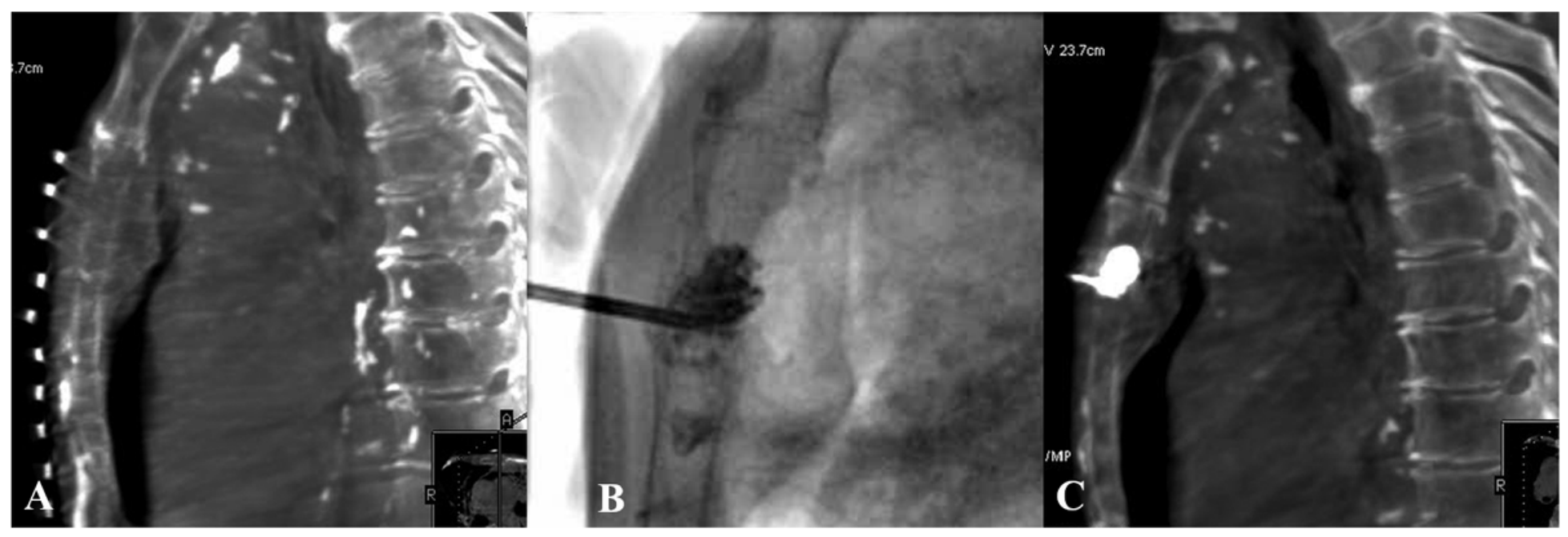

Figure 3

(A) CBCT sagital image showed a diffuse osteolytic lesion of the sternal body and manubrium. (B) Radiograph showed the second needle inserted into the center of the lesion. (C) CBCT sagital image showed PMMA distribution. 


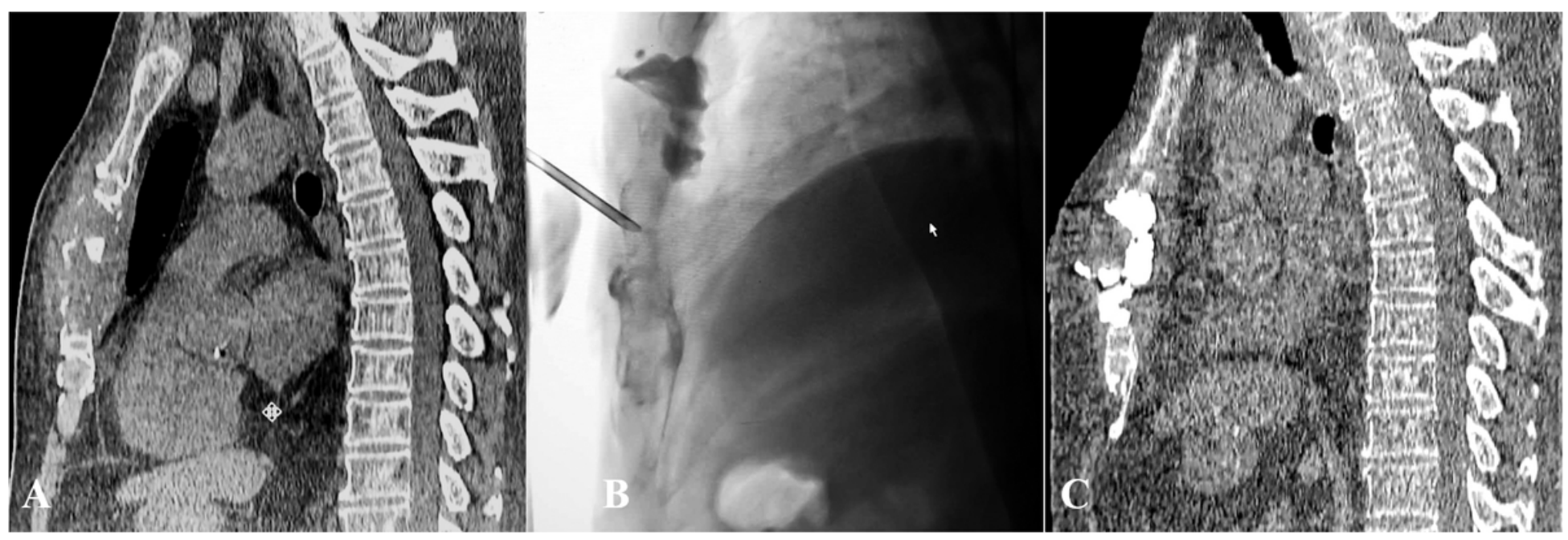

Figure 4

(A) CBCT sagital image showed a diffuse osteolytic lesion of the sternal body and manubrium. (B) Radiograph showed the third needle inserted into the center of the lesion. (C) CBCT sagital image showed PMMA distribution. 